\title{
DISCRETE-TIME SLIDING MODE CONTROL FOR PLANTS WITH STABLE FINITE ZERO
}

\author{
Olivera Iskrenovic-Momcilovic
}

Original scientific paper

A method for practical implementation of discrete-time sliding mode control technique for control of plants with stable finite zero is proposed in this paper. The method is based on a combination of different conventional and sliding mode control approaches. The control system contains a sliding mode controller, an observer, based on nominal plant model without finite zero, and two additional control channels for the plant and for the plant model. The main attention in the paper is directed to the stability of the proposed system structure with respect to exogenous disturbances. The effectiveness of the proposed control strategy is demonstrated by simulation on an example.

Keywords: discrete-time systems; plant with finite zero; sliding mode control; variable structure system

Diskretno upravljanje kliznim režimom rada za objekte sa stabilnom konačnom nulom

Izvorni znanstveni članak U ovom se radu predlaže metoda za praktičnu implementaciju tehnike diskretnog kliznog režima rada za upravljanje objektima sa stabilnom konačnom nulom. Metoda se temelji na kombinaciji različitih pristupa upravljanja od konvencionalnih do onih koji se temelje na kliznom režimu rada. Sustav kontrole sadrži regulator kliznog režima rada, opserver na temelju nominalnog modela objekta bez konačne nule i dva dodatna kontrolna kanala za objekt $\mathrm{i}$ model objekta. Glavna pozornost u radu je usmjerena na stabilnost predloženog sustava u odnosu na vanjski poremećaj. Učinkovitost predložene strategije upravljanja pokazana je simulacijom na jednom primjeru.

Ključne riječi: diskretni sustav; klizni režim rada; objekat s konačnom nulom; sustav varijabilne strukture

\section{Introduction}

The variable structure control systems (VSCS) are dominantly used for control of plants without finite zeros. Control of plants with finite zeros using VSCS has some specifities $[1 \div 6]$. Namely, differential features of the controlled plant and the applied high frequency pulse train control make control system phase state coordinates non smooth functions. Therefore, it is not possible to obtain sliding mode on a predefined sliding surface with above given features using standard methods of the VSCS synthesis.

The above mentioned problem has been observed on the early beginning of the VSCS investigation. There have been proposed two approaches [7, 8]. First of them has been introduction of the inertial filters between the sliding mode controller and the plant. The second approach was based on system state coordinate transformation. This method was later [9] generalized as a method of the sliding mode organization in the canonical subspace of the system. All of the above given approaches may be used for control of plants with stable finite zeros. Control of the plants with unstable finite zeros is a much cumbersome problem. An approach for this type of plant is suggested by Stessel and Shkolnikov [10]. In the present paper we propose a new control structure for control of a high order plant with a stable finite zero using sliding mode approach.

The paper is organized as follows: in the next section the suggested control structure will be presented. Then, in the third section, some preliminary control system design considerations will be given. The system stability problem will be analysed in the fourth section. In the fifth section two illustrative examples for second-order and third-order plant controller design will be given, and verified by simulation.

\section{Control system structure 2.1 System model}

The proposed control system structure is depicted in Fig. 1. In the given scheme, reduced plant without finite zero (RPL) provides estimation of canonical controllable coordinates of the plant (PL), which are necessary for sliding mode control realization. Namely, under assumption that the outputs of the PL and the RPL are the same at every time moment, then its canonical state coordinates will be identical also. Taking into consideration that the PL parameters are liable to changes, and it is exposed to load action, with the aim to provide condition of equality of the mentioned outputs, new control channels must be introduced. These control channels are based on difference within the PL and the RPL outputs. The first additional control channel (CRPL) is directed to the RPL input, and makes conventional state observer structure [11]. The second control channel (CPL) is a new control which acts at the PL input. This control is not conventional. Its introduction may be necessary to guarantee asymptotic stability of the control system and its robustness to the disturbances.

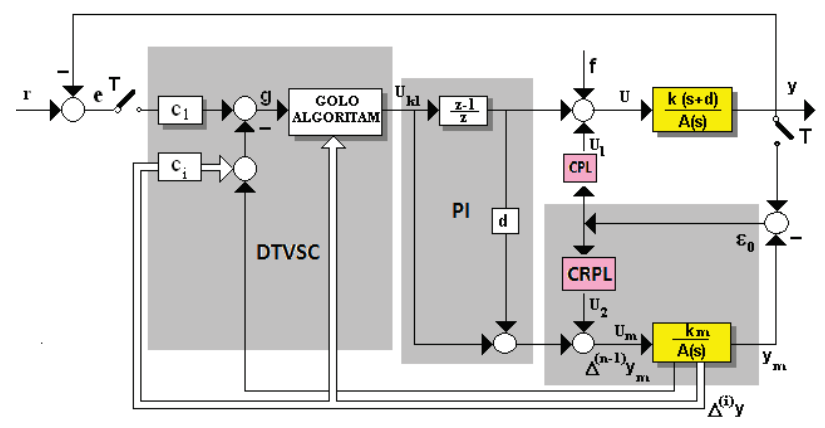

Figure 1 Block diagram of system 
The proposed system structure is based on the fact that the introduction of a proportional-integral (PI) action between the discrete-time variable structure controller (DTVSC) and the PL without finite zeros does not violate sliding mode existence conditions established for the system without the introduced PI action [12]. The main problem in the proposed control structure is how to preserve system stability in the presence of the exogenous disturbance $f(t)$.

\subsection{Conditions of existence of sliding mode}

Suppose we have a complete and fully controllable PL with limited parametric perturbations, with a single input single output is described transfer function:

$$
W_{o b}(s)=\frac{k(s+d)}{A(s)},
$$

where:

$d$ - stable zero $\left(d_{\min } \leq d \leq d_{\max }\right)$,

$k$ - amplification of the plant $\left(k_{\min } \leq k \leq k_{\max }\right)$,

$$
A(s)=s^{n}+\sum_{i=1}^{n} a_{i} s^{i-1}\left(a_{\min } \leq a \leq a_{\max }\right) .
$$

It is assumed that the system parameters are nonstationary, but with the speed of change is much smaller than the dynamics of the process that takes place in a control system.

At the input of the plant is introduced integral (I) action, so that the extended transfer function of the plant becomes:

$W_{o b}^{P}(s)=\frac{s+d}{s} \frac{k}{A(s)}=\left(1+\frac{d}{s}\right) \frac{k}{A(s)}$

Extended plant can be seen as a plant without stable finite zero, which is added to PI action with constant parameters. In addition to the expanded plant is introduced the reduced plant with nominal values of the parameters without finite zero. This reduced plant describes the transfer function:

$$
W_{o b}^{R}(s)=\frac{k_{m}}{A(s)}
$$

Mathematical model of reduced plant (1) in the canonical controllable form:

$$
\dot{\boldsymbol{x}}(t)=\boldsymbol{A} \boldsymbol{x}(t)+\boldsymbol{b} u(t)
$$

where:

$$
\boldsymbol{A}=\left[\begin{array}{ccccc}
0 & 1 & 0 & \ldots & 0 \\
0 & 0 & 1 & \ldots & 0 \\
\ldots & \ldots & \ldots & \ldots & \ldots \\
-a_{1} & -a_{2} & -a_{3} & \ldots & -a_{n}
\end{array}\right], \boldsymbol{b}=\left[\begin{array}{c}
0 \\
0 \\
\ldots \\
k
\end{array}\right]
$$

This reduced model of the plant can be realized by computer (discretely). Equivalent discrete-time model of the system (2) is [13]:

$$
\delta \boldsymbol{x}(k)=\boldsymbol{A}_{\boldsymbol{\delta}} \boldsymbol{x}(k)+\boldsymbol{b}_{\boldsymbol{\delta}} u(k),
$$

where:

$\boldsymbol{A}_{\boldsymbol{\delta}}=\frac{\mathrm{e}^{\boldsymbol{A} T}-\boldsymbol{I}}{T}, \quad \boldsymbol{b}_{\boldsymbol{\delta}}=\frac{1}{T} \int_{0}^{T} \mathrm{e}^{\boldsymbol{A} \tau} \boldsymbol{b} \mathrm{d} \tau$.

The expression of these relations $\delta \boldsymbol{x}(k)$ is a replacement for the first differential:

$$
\delta \boldsymbol{x}(k)=\frac{\boldsymbol{x}(k+1)-\boldsymbol{x}(k)}{T}
$$

Let the sliding hyper plane be defined by [13]:

$g(k)=c_{\delta} \boldsymbol{x}(k)$,

where:

$$
\begin{aligned}
\delta_{i} & =\frac{\mathrm{e}^{-\alpha_{i} T}-1}{T}, \quad \alpha_{i}>0, \quad i=1, \ldots, n-1, \\
\boldsymbol{c}_{\boldsymbol{\delta}} & =\left[\begin{array}{lllll}
c_{1} & c_{2} & \ldots & c_{n-1} & 1
\end{array}\right] \boldsymbol{P}^{-1}, \\
\boldsymbol{P} & =\left[\begin{array}{lllll}
\boldsymbol{b}_{\boldsymbol{\delta}} & \ldots & \boldsymbol{A}_{\boldsymbol{\delta}}^{\boldsymbol{n}-\boldsymbol{1}} & \boldsymbol{b}_{\boldsymbol{\delta}}
\end{array}\right]\left[\begin{array}{ccccc}
\overline{a_{1}} & \ldots & \overline{a_{n-1}} & 1 \\
a_{2} & \ldots & 1 & 0 \\
\ldots & \ldots & \ldots & \ldots \\
1 & \ldots & 0 & 0
\end{array}\right],
\end{aligned}
$$

$\bar{a}_{i}$ - coefficient of the characteristic polynomial

$\operatorname{det}\left(z \boldsymbol{I}-\boldsymbol{A}_{\boldsymbol{\delta}}\right)=z^{n}+\bar{a}_{n-1} z^{n-1}+\ldots+\bar{a}_{1} z+\bar{a}_{0}$.

For the discrete-time model of reduced plant (3) can be synthesized control in the form:

$$
\begin{aligned}
u_{k l}(k)= & -c_{\boldsymbol{\delta}} \boldsymbol{A}_{\boldsymbol{\delta}} \boldsymbol{x}(k)- \\
& -\min \left(\frac{|g(k)|}{T}, \alpha+\beta|g(k)|\right) \operatorname{sgn}(g(k)),
\end{aligned}
$$

where:

$\alpha, \beta$ - real numbers such that $0 \leq \beta T<1$ and $\alpha>0$.

We are considering the plant model. However, it is de facto, with feedback by CRPL, an observer in its basic sense. The feedback CRPL must be of PI type for obtaining zero observation error in presence of slow varying disturbance. At the PL input could be introduced an additional action from the observation error signal, over the element CPL, if the asymptotic stability of the observer error control loop may not be obtained after introducing CRPL or to improve control system dynamics. Type and parameters of this action must be determined according to preserve system stability and desired observation error transient dynamics. The next section will be dedicated to this problem solving. 


\section{System stability}

If the stable sliding mode is organized on the hyperplane (4) with desired dynamics, since the plant model is in canonical controllable form, the matching conditions [14] are satisfied. This means that the control loop with CRPL will be invariant to the bounded disturbances. If the observation error asymptotically tends to zero, the CRPL disturbance will be bounded and the system stability will be preserved. Under assumption that the plant parameter uncertainties may be treated as additional disturbance which acts at the plant input, to guarantee the asymptotic stability of the observation error process, it may be necessary to introduce an additional compensator CPL with adequate type and parameters.

The CRPL is usually determined so as to obtain observer dynamics faster than the plant dynamics. Further, for the avoidance of the observer insensitivity to the slow varying disturbances, the CRPL must have a PI structure. Based on the given assumption only CPL structure and parameters must be determined. It may be recommended, if the stability and desired dynamics are preserved, to choose CRPL and CPL identical.

From the given block diagram (Fig. 1), observation error dynamics with respect to the disturbance may be described as

$$
\varepsilon_{0}(z)=\frac{W_{o b}(z)}{1+W_{o b}(z) W_{C P L}(z)-W_{o b}^{R}(z) W_{C R P L}(z)} f(z)
$$

Then the design is concentrated to the selection of $W_{C P L}(z)$ which enables the characteristic equation of the system (7):

$$
P(z)=1+W_{o b}(z) W_{C P L}(z)-W_{o b}^{R}(z) W_{C R P L}(z)=0,
$$

has all its roots inside the unit circle $|z|=1$ in the $z$-plane with adequate location to obtain satisfactory transient dynamics with respect to disturbance rejection process.

Checking the root of the characteristic Eq. (8) can be done by applying some of the criteria of stability, for example by applying Jury stability test. The characteristic Eq. (8) can be written in the form:

$$
P(z)=p_{n} z^{n}+p_{n-1} z^{n-1}+\ldots+p_{1} z+p_{0} .
$$

Now it gets Jury's scheme coefficients in the form [15]:

$$
\begin{aligned}
q_{i} & =\left|\begin{array}{cc}
p_{0} & p_{n-i} \\
p_{n} & p_{i}
\end{array}\right|, \quad i=0, \ldots n-1, \\
r_{j} & =\left|\begin{array}{cc}
q_{0} & q_{n-i-j} \\
q_{n-1} & q_{j}
\end{array}\right|, \quad j=0, \ldots n-2, \\
s_{k} & =\left|\begin{array}{cc}
r_{0} & r_{n-2-k} \\
r_{n-2} & r_{k}
\end{array}\right|, \quad k=0, \ldots n-3, \\
\ldots . . . & \\
t_{0} & =\left|\begin{array}{ll}
u_{0} & u_{3} \\
u_{3} & u_{0}
\end{array}\right|, t_{1}=\left|\begin{array}{ll}
u_{0} & u_{2} \\
u_{3} & u_{1}
\end{array}\right|, t_{2}=\left|\begin{array}{ll}
u_{0} & u_{1} \\
u_{3} & u_{2}
\end{array}\right| .
\end{aligned}
$$

The necessary and sufficient conditions that Eq. (10) has all roots modulo less than one and that the system is stable are:

$$
\begin{aligned}
& P(1)>0, \quad(-1)^{n} P(-1)>0, \quad\left|p_{0}\right|<\left|p_{1}\right|, \\
& \left|q_{0}\right|>\left|q_{n-1}\right|, \quad\left|r_{0}\right|>\left|r_{n-2}\right|, \quad \ldots . \quad\left|t_{0}\right|>\left|t_{2}\right|
\end{aligned}
$$

\section{Illustrative example}

In order to validate the proposed method combination of variable structure control law with flexible working regimes of linear control law and PI-type discrete-time VSCS is designed and simulated on the PC to control a third order plant with stable finite zero:

$$
\begin{aligned}
& W_{o b}(z)=\frac{k(s+d)}{s^{3}+a_{3} s^{2}}, \\
& 1,8 \leq a_{3} \leq 2,2, \quad 15 \leq k \leq 20, \quad 0,08 \leq d \leq 0,12 . \\
& f(t)=0,1[h(t-4)-h(t-7)] .
\end{aligned}
$$

We introduce a model of reduced plant with nominal values of parameters without finite stable zero of the form:

$$
W_{o b}^{R}(z)=\frac{10}{s^{3}}
$$

Continuous model reduced plant (12) in state space is:

$$
\left[\begin{array}{c}
\dot{x_{1}(t)} \\
\dot{x_{2}(t)} \\
x_{3}(t)
\end{array}\right]=\left[\begin{array}{ccc}
0 & 1 & 0 \\
0 & 0 & 1 \\
0 & 0 & -2
\end{array}\right]\left[\begin{array}{c}
x_{1}(t) \\
x_{2}(t) \\
x_{3}(t)
\end{array}\right]+\left[\begin{array}{c}
0 \\
0 \\
10
\end{array}\right] u(t)
$$

According to the theorem on selection, was chosen sampling time $T=0,1 \mathrm{~ms}$. By $\delta$ applying the transformation for the selected sampling time, a discretetime model of the system (13) according to Eq. (3) becomes:

$$
\left[\begin{array}{l}
\delta x_{1}(k) \\
\delta x_{2}(k) \\
\delta x_{3}(k)
\end{array}\right]=\left[\begin{array}{ccc}
0 & 1 & 0,0020 \\
0 & 0 & 0,9996 \\
0 & 0 & -1,9992
\end{array}\right]\left[\begin{array}{l}
x_{1}(k) \\
x_{2}(k) \\
x_{3}(k)
\end{array}\right]+\left[\begin{array}{c}
0 \\
0,002 \\
9,996
\end{array}\right] u(k) .
$$

If we choose $\alpha_{1}=2$ and $\alpha_{2}=2$, the elements of the vector $c_{\delta}(5)$ become:

$$
\boldsymbol{c}_{\boldsymbol{\delta}}=\left[\begin{array}{lll}
-0,20008 & -0,40008 & -0,09996
\end{array}\right] \text {. }
$$

Let $\alpha=50$ and $\beta=50$. Control (6) is:

$$
\begin{aligned}
u(k) & =-0,2008 x_{2}(k)-0,20048 x_{3}(k)+ \\
& +\min (2500|g(k)|, 50+20|g(k)|),
\end{aligned}
$$

and the sliding hyper plane (4) is:

$$
g(k)=-0,20008 e(k)+0,40008 x_{2}(k)+0,09996 x_{1}(k) .
$$


To ensure the robustness of the system to parameter changes of the plant and the external disturbance is introduced by the feedback signal observation errors between the outputs of the plant and the model, as shown in Fig. 1. CPL and CRPL were chosen in the following form:

$$
W_{C P L}(z)=W_{C R P L}(z)=200 \frac{2 z-1}{z}
$$

The characteristic equation errors of observation (9) are:

$$
\begin{aligned}
& z^{4}-2,9992 z^{3}+2,998408 z^{2}- \\
& -0,999216256 z+0,000000128=0 .
\end{aligned}
$$

Based on the relation (10) is obtained Jury's scheme coefficients of the form and conditions (11) are:

$$
\begin{aligned}
& 0,007192>0, \quad 7,996824>0, \quad|0,000000128|<1, \\
& |-0,999999|>|0,999216|, \quad|0,001567|>|0,001559| .
\end{aligned}
$$

Since all the conditions (15) are met and the characteristic equation (14) has all roots modulo less than one, was the stability of the circuit of observation error.

For the illustration of the qualities of the proposed control system, it is compared with a conventional control system with proportional-integral (PI) controller with transfer function which has similar rise-time as the proposed control system.

$$
W_{P I D}(z)=5 \frac{z-1}{z}
$$

In Fig. 2 the unit step responses of the compared control systems are given. It is evident that the proposed control system has much better dynamics (faster settling time, no overshoot and practically is not sensitive to the given load disturbance).

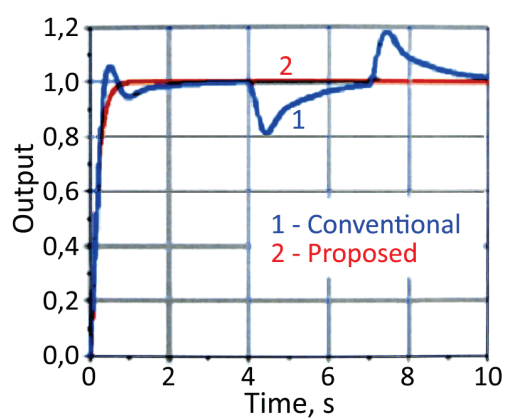

Figure 2 Step responses

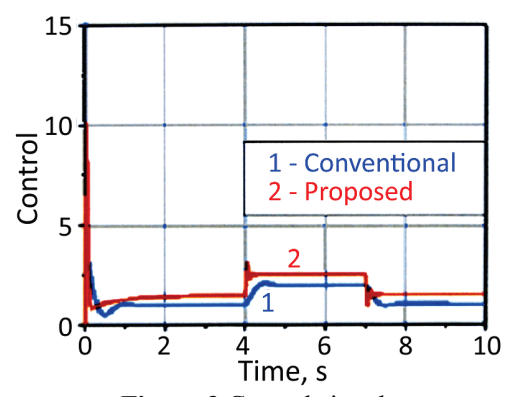

Figure 3 Control signals
From Fig. 3 it can be seen that the control signals of both compared control systems are not too much different in its values, but the control signal of the proposed control system has faster dynamics which enables faster regulation process and faster rejection of the load disturbance.

Moreover, control signal applied to the plant input is smooth. Therefore chattering phenomenon as one of the serious drawbacks of the sliding mode control system approach does not exist.

\section{Conclusion}

A new sliding mode control structure, for the effective control of the dynamic plants with stable finite zero, was presented in this paper. A combination of variable structure control law is suggested with flexible working regimes of linear control law and PI type for a high quality control system robust to changing the parameters of the plant and the effect of external disturbances. To obtain pieces of information about the differential controlled variable observer is used, designed on the basis of the reference model of the plant without finite zero, using appropriate feedback loops for signal observation error.

At the plant input an integral action has been introduced. Then, the nominal transfer functions of the plant with the additional integral term and the reference model with additional PI term are identical. Because the plant is usually disturbed by internal and external disturbances, we introduce two correction channels, with respect to the mismatch between the plant and the reference model outputs. One correction channel is for the reference model which makes the conventional observer structure. The second correction channel was introduced to the plant input. The latter correction channel is a new idea which gives very satisfactory properties in the regulation process especially in the capability of disturbance rejection.

\section{References}

[1] Iskrenovic-Momcilovic, O. Improvement of characteristic of discrete-time variable structure controller for plants with finite zeros. // Annals of Faculty engineering Hunedoara International Journal of Engineering. 11, 2(2013), pp. 183188.

[2] Iskrenovic-Momcilovic, O. Discrete-time variable structure controller synthesis using model in canonical subspace. // International Review of Automatic Control. 5, 5(2012), pp. 703-709.

[3] Iskrenovic-Momcilovic, O. Application of discrete-time quasi-sliding modes in controlling of objects with finite zeros, Ph. D. Thesis, University of Nis (in Serbian), 2006.

[4] Iskrenovic-Momcilovic, O. Discrete-time variable structure controller synthesis for third order objects with finite zero using delta transform. // Journal of Electrical Engineering. 55, 3-4(2004), pp. 71-76.

[5] Milosavljevic, C.; Perunicic-Drazenovic, B.; Veselic, B. A sliding-mode control strategy for objects with a stable finite zero. // Proceedings of the $8^{\text {th }}$ International workshop on variable structure systems / Antalya, 2008, pp. 262-267. DOI: $10.1109 /$ vss.2008.4570718 
[6] Milosavljevic, C.; Pejovic, M.; Milosavljevic, G. Sliding mode control of thrid-order objects with stable finite zero. // Proceedings of the ICEST / Sofia, 2003, pp. 365-368.

[7] Kostyleva, N. E. Using of variable structure systems for control objects with finite zeros. // Proceedings Theory and application of automatic control systems / Moscow, 1964.

[8] Yemelyanov, S. V. Variable structure control systems theory. Moscow : Science, 1970.

[9] Utkin, V. I. Sliding Modes in Control and Optimization, New Yourk : Springer Verlag, 1993.

[10] Stessel, Y. B.; Shkolnikov, I. A. Output tracking in causal nonminimum-phase systems using sliding modes. // Variable structure systems: from principles to implementation / Sabanovic A.; Fridman, L.; Spurgeon, S.; The IEE Press, 2004.

[11] Luenberger, D. G. An introduction to observers. // IEEE Transactions on Automatic Control. 16, 6(1971), pp. 596602. DOI: 10.1109/TAC.1971.1099826

[12] Milosavljevic, C. Variable structure systems of quasi-relay type with proportional-integral action. // Facta universitatis: Mechanics, Automatic Control and Robotics. 2, 7(1997), pp. 301-314.

[13] Golo, G.; Milosavljevic, C. Robust discrete-time chatteringfree sliding mode control. // Systems and Control Letters. 41(2000), pp. 19-28. DOI: 10.1016/S0167-6911(00)00033-5

[14] Drazenovic, B. The invariance conditions in variable structure systems. // Automatica. 5, 3(1969), pp. 287-295. DOI: 10.1016/0005-1098(69)90071-5

[15] Stojic, M. Digital control systems, Beograd : Scinece, 1990.

\section{Author's address}

Olivera Iskrenovic-Momcilovic, Assistant Professor

University of Novi Sad,

Faculty of Education,

Podgoricka 4, 25000 Sombor, Serbia

E-mail: oljkaisk@yahoo.com 